\title{
Power Compensation using Fuzzy Logic Based For Grid Interactive PV System
}

\author{
V.Dega Rajaji ${ }^{1}$, D.Akhila John ${ }^{2}$, D.Amulya John ${ }^{3}$
}

\begin{abstract}
Photovoltaic (PV) cell characteristics are highly nonlinear that gives single Maximum Power Point (MPP) on $\mathrm{P}-\mathrm{V}$ curve under uniform insolation condition. The characteristics and hence MPP point changes with the variation in insolation and temperature. In order to extract a maximum power from PV array, a fuzzy based MPP tracking algorithm is proposed. The algorithm accepts single input that is slope of $\mathrm{P}-\mathrm{V}$ curve and generates the duty ratio as an output that operates the boost converter to track MPP. The algorithm gives faster convergence by applying variable step in duty ratio and gives accurate MPP. The two stage grid interactive PV system described in this paper supplies active power as well as provides harmonic and reactive power compensation. This additional feature increases the effective utilization of PV inverter and increases the overall efficiency of the system. The simulation results validate the performance and stability of the grid interactive PV system using the proposed algorithm for active current injection as well as harmonics and reactive power compensation.
\end{abstract}

Keywords: Photovoltaic system, maximum power point tracking, fuzzy logic controller, harmonic elimination, reactive power compensation

\section{INTRODUCTION}

In our world today, the problems caused by global warming and pollution effect become the important issues for research. Renewable energy sources are considered as a technological option for generating clean energy. Among them, photovoltaic (PV) system has received a great attention as it appears to be one of the most promising renewable energy sources. Recently, due to its development and cost reduction, PV system becomes an efficient solution to the environmental problem. However, the development for improving the efficiency of the PV system is still a challenging field of research. PV system cannot be modeled as a constant DC current source because its output power is varied depending on the load current, temperature and irradiation. Generally, MPPT is adopted to track the maximum power point in the PV system. The efficiency of MPPT depends on both the MPPT control algorithm and the MPPT circuit. The MPPT control algorithm is usually applied in the DC-DC converter, which is normally used as the MPPT circuit.

One of the most popular algorithms of MPPT is P\&O (Perturb and Observe) technique; however, the convergence problem and oscillation are occurred at certain points during the tracking. To enhance the performance of the $\mathrm{P} \& \mathrm{O}$ algorithm, this paper presents the application of Fuzzy Logic Control (FLC) to the MPPT control. Photovoltaic (PV) generation is becoming increasingly important as a renewable source since it offers many advantages such as incurring no fuel costs, not being polluting, requiring little maintenance, and emitting no noise, among others. PV modules still have relatively low conversion efficiency; therefore, controlling maximum power point tracking (MPPT) for the solar array is essential in a PV system.

The amount of power generated by a PV depends on the operating voltage of the array. A PV's maximum power point (MPP) varies with solar insulation and temperature. Its V-I and V-P characteristic curves specify a unique operating point at which maximum possible power is delivered. At the MPP, the PV operates at its highest efficiency. Therefore, many methods have been developed to determine MPPT. In MPPT, most control schema use the $\mathrm{P} \& \mathrm{O}$ technique because it is easy to implement. But the oscillation problem is unavoidable. This research developed an extended $\mathrm{P} \& \mathrm{O}$ technique - a three-point weight comparison method based on an 8-bit single-chip control unit - by utilizing a boost converter to adjust the output voltage of the PV for tracking the MPP. Models and simulations of this PV system and MPPT algorithms are offered with experimental results

\subsection{PHOTOVOLTAIC SYSTEMS}

Photovoltaic systems are composed of interconnected components designed to accomplish specific goals ranging from powering a small device to feeding electricity into the main distribution grid [1]. Photovoltaic systems are classified according to the diagram in Figure 1.1. The two main general classifications as depicted in the figure are the stand-alone and the grid-connected systems. The main distinguishing fact tor between these two systems is that in stand-alone systems the solar energy output is matched with the load demand. To cater for different load patterns, storage elements are generally used and most systems currently use batteries for storage. If the PV system is used in conjunction with another power source like a wind or diesel generator then it falls under the class of hybrid systems.

The balances of system (BOS) components are a major contribution to the life cycle costs of a photovoltaic system. They include all the power conditioning units, storage elements and mechanical structures that are needed. They especially have a huge impact on the operating costs of the PV system. 


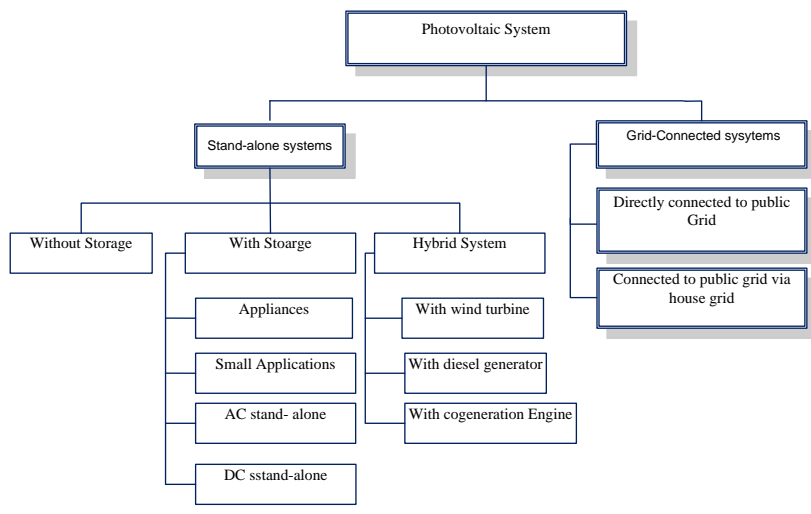

Fig 1.1: Classification of PV systems

\subsection{PV MODULE}

For the majority of applications multiple solar cells need to be connected in series or in parallel to produce enough voltage and power. Individual cells are usually connected into a series string of cells (typically 36 or 72) to achieve the desired output voltage. The complete assembly is usually referred to as a module and manufacturers basically sell modules to customers. The modules serves another function of protecting individual cells from water, dust etc. as the solar cells are placed into an encapsulation of single or double at glasses

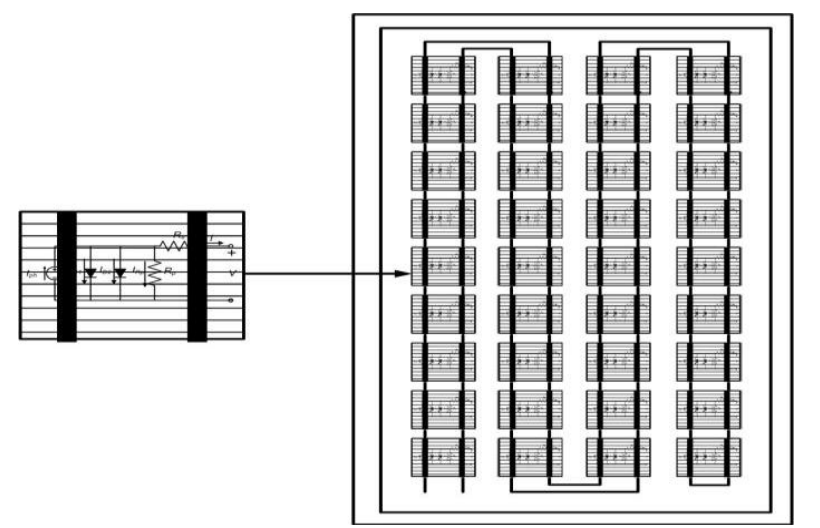

Fig 1.2: Structure of a PV module with 36 cells connected in series

Within a module the different cells are connected electrically in series or in parallel although most modules have a series connection. Figure 1.3 shows a typical connection of how 36 cells are connected in series. In a series connection the same current flows through all the cells and the voltage at the module terminals is the sum of the individual voltages of each cell. It is therefore, very critical for the cells to be well matched in the series string so that all cells operate at the maximum power points. When modules are connected in parallel the current will be the sum of the individual cell currents and the output voltage will equal that of a single cell.

\subsection{PV CELL MODEL}

The equivalent circuit of a PV cell is shown in Fig.1.3. It includes a current source, a diode, a series resistance and a shunt resistance.

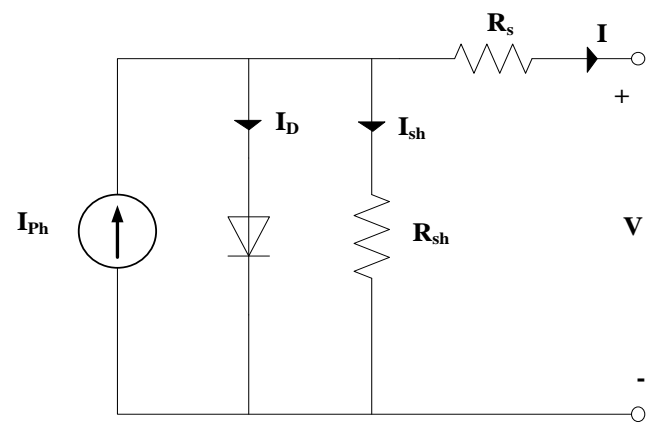

Fig 1.3 PV cell equivalent circuit.

In view of that, the current to the load can be given as

$$
\left.\mathrm{I}=I_{p h}-I_{S}\left(\exp \frac{q\left(V+R_{S} \mathrm{I}\right)}{N K T}\right)-1\right)-\frac{\left(V+R_{S} \mathrm{I}\right)}{R_{s h}}
$$

In this equation, $I_{p h}$ is the photocurrent, $I_{s}$ is the reverse saturation current of the diode, $q$ is the electron charge, $V$ is the voltage across the diode, $K$ is the Boltzmann's constant, $T$ is the junction temperature, $N$ is the ideality factor of the diode, and $R_{s}$ and $R_{s h}$ are the series and shunt resistors of the cell, respectively. As a result, the complete physical behavior of the PV cell is in relation with $I_{p h}, I_{s}$, $R_{s}$ and $R_{s h}$ from one hand and with two environmental parameters as the temperature and the solar radiation from the other hand.

\subsection{MAXIMUM POWER POINT TRACKER}

Maximum power point tracking (MPPT) is a technique that grid-tie inverters, solar battery chargers and similar devices use to get the maximum possible power from one or more photovoltaic devices, typically solar panels, though optical power transmission systems can benefit from similar technology. Solar cells have a complex relationship between solar irradiation, temperature and total resistance that produces a non-linear output efficiency which can be analyzed based on the I-V curve. It is the purpose of the MPPT system to sample the output of the cells and apply the proper resistance (load) to obtain maximum power for any given environmental conditions. MPPT devices are typically integrated into an electric power converter system that provides voltage or current conversion, filtering, and regulation for driving various loads, including power grids, batteries, or motors.

Photovoltaic cells have a complex relationship between their operating environment and the maximum power they can produce. The fill factor, abbreviated $F F$, is a parameter which characterizes the non-linear electrical behavior of the solar cell. Fill factor is defined as the ratio of the maximum power from the solar cell to the product of open Circuit Voltage $V_{\mathrm{oc}}$ and Short-Circuit Current $\mathrm{I}_{\mathrm{sc}}$. In tabulated data it is often used to estimate the maximum power that a cell can provide with an optimal load under given conditions, $P=F F^{*} V_{o c} * I_{s c}$. For most purposes, FF, $V_{\mathrm{oc}}$, and $\mathrm{I}_{\mathrm{sc}}$ are enough information to give a useful approximate model of the electrical behavior of a photovoltaic cell under typical conditions.

For any given set of operational conditions, cells have a single operating point where the values of the current $(I)$ and Voltage $(V)$ of the cell result in a maximum power output. These values correspond to a particular load resistance, which is equal to $V / \mathrm{I}$ as 
specified by Ohm's Law. The power $\mathrm{P}$ is given by $P=V^{*} I$. Correspondingly, the elements $\mathrm{Ci}$ are the fuzzy variables A photovoltaic cell, for the majority of its useful curve, acts as constant current source. However, at a photovoltaic cell's MPP region, its curve has an approximately inverse exponential relationship between current and voltage. From basic circuit theory, the power delivered from or to a device is optimized where the derivative (graphically, the slope) $d I / d V$ of the $\mathrm{I}-\mathrm{V}$ curve is equal and opposite the $\mathrm{I} / V$ ratio (where $\mathrm{d} P / d V=0$ ). This is known as the maximum power point (MPP) and corresponds to the "knee" of the curve.

A load with resistance $R=V / I$ equal to the reciprocal of this value draws the maximum power from the device. This is sometimes called the characteristic resistance of the cell. This is a dynamic quantity which changes depending on the level of illumination, as well as other factors such as temperature and the age of the cell. If the resistance is lower or higher than this value, the power drawn will be less than the maximum available, and thus the cell will not be used as efficiently as it could be. Maximum power point trackers utilize different types of control circuit or logic to search for this point and thus to allow the converter circuit to extract the maximum power available from a cell.

\subsection{The Fuzzy Logic Concept}

Fuzzy logic arose from a desire to incorporate logical reasoning and the intuitive decision making of an expert operator into an automated system . The aim is to make decisions based on a number of learned or predefined rules, rather than numerical calculations. Fuzzy logic incorporates a rule-base structure in attempting to make decisions. However, before the rule-base can be used, the input data should be represented in such a way as to retain meaning, while still allowing for manipulation. Fuzzy logic is an aggregation of rules, based on the input state variables condition with a corresponding desired output. A mechanism must exist to decide on which output, or combination of different outputs, will be used since each rule could conceivably result in a different output action.

Fuzzy logic can be viewed as an alternative form of input=output mapping. Consider the input premise, $\mathrm{x}$, and a particular qualification of the input $\mathrm{x}$ represented by Ai. Additionally, the corresponding output, $y$, can be qualified by expression $\mathrm{Ci}$. Thus, a fuzzy logic representation of the relationship between the input $\mathrm{x}$ and the output $\mathrm{y}$ could be described by the following:

$\mathrm{R} 1$ : IF $\mathrm{x}$ is $\mathrm{A} 1$ THEN $\mathrm{y}$ is $\mathrm{C} 1$

$\mathrm{R} 2$ : IF $\mathrm{x}$ is $\mathrm{A} 2$ THEN $\mathrm{y}$ is $\mathrm{C} 2$

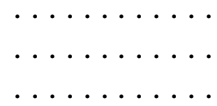

$\mathrm{Rn}$ : IF $\mathrm{x}$ is An THEN $\mathrm{y}$ is $\mathrm{Cn}$

where $\mathrm{x}$ is the input (state variable), $\mathrm{y}$ is the output of the system, $\mathrm{Ai}$ are the different fuzzy variables used to classify the input $\mathrm{x}$ and $\mathrm{Ci}$ are the different fuzzy variables used to classify the output $y$. The fuzzy rule representation is linguistically based .

Thus, the input $\mathrm{x}$ is a linguistic variable that corresponds to the state variable under consideration. Furthermore, the elements Ai are fuzzy variables that describe the input $\mathrm{x}$. used to describe the output y. In fuzzy logic control, the term "linguistic variable" refers to whatever state variables the system designer is interested in . Linguistic variables that are often used in control applications include Speed, Speed Error, Position, and Derivative of Position Error. The fuzzy variable is perhaps better described as a fuzzy linguistic qualifier. Thus the fuzzy qualifier performs classification (qualification) of the linguistic variables. The fuzzy variables frequently employed include Negative Large, Positive Small and Zero.

Several papers in the literature use the term "fuzzy set" instead of "fuzzy variable", however; the concept remains the same. Table 30.1 illustrates the difference between fuzzy variables and linguistic variables. Once the linguistic and fuzzy variables have been specified, the complete inference system can be defined.

The fuzzy linguistic universe, $U$, is defined as the collection of all the fuzzy variables used to describe the linguistic variables .

i.e. the set $U$ for a particular system could be comprised of Negative Small (NS), Zero (ZE) and Positive Small (PS). Thus, in this case the set $\mathrm{U}$ is equal to the set of [NS, ZE, PS]. For the system described by Eq. (30.1), the linguistic universe for the input $\mathrm{x}$ would be the set Ux . A1A2 . . An.. Similarly,

TABLE 1 Fuzzy and linguistic variables

\begin{tabular}{llll}
\hline Linguistic Variables & $\begin{array}{l}\text { Furzy Variables (Linguistic Quali- } \\
\text { fiers) }\end{array}$ & \\
\hline Speed error & (SE) & Negative large & (NL) \\
Position error & (PE) & Zero & (ZE) \\
Acceleration & $(\mathrm{AC})$ & Positive medium & (PM) \\
Derivative of & $(\mathrm{DPE})$ & Positive very small & (PVS) \\
$\begin{array}{l}\text { position error } \\
\text { Speed }\end{array}$ & (SP) & Negative medium small & (NMS) \\
\hline
\end{tabular}

\subsection{PROPOSED CONCEPT}

\subsection{PV ARRAY MODELLING AND CHARACTERISTICS}

The PV array is made up of number of PV modules connected in series called string and number of such strings connected in parallel to achieve desired voltage and current. The PV module used for simulation study consists of 36 series connected polycrystalline cells

\section{A. PV Model}

The electrical equivalent circuit model of PV cell consists of a current source in parallel with a diode as shown in Fig. 1.3.$$
I_{P V}=I_{P h}-I_{D}-I_{s h}
$$
where,$$
I_{D}=I_{O}\left(e^{\frac{q\left(V_{P V}+I_{P V} R_{S}\right)}{\eta k T}}-1\right)
$$$$
\text { and }
$$$$
I_{s h}=\frac{V_{P V}+I_{P V} R_{S}}{R_{s h}}
$$ 
The parameters $q, \eta, k$ and $T$ denote the electronic charge, PROPOSED MPPT ALGORITHM

ideality factor of the diode, Boltzmann constant and From the simulated I-V and P-V characteristics of the PV temperature in Kelvin respectively. $I_{p h}$ is photocurrent, $I O$ module, it can be seen that the characteristics are highly is diode reverse saturation current, $I_{P V}$ and $V_{P V}$ are the PV nonlinear. Also, there is single point on P-V curve where output current and voltage respectively.

As the value of $R s h$ is very large, it has a negligible effect on the I-V characteristics of PV cell or array. Thus (1.1) can be simplified to

$$
I_{P V}=I_{p h}-I_{o}\left(e^{\frac{q\left(V_{P V}+I_{P V} R_{S}\right)}{\eta k T}}-1\right)
$$

For PV array consisting of $\mathrm{Ns}$ series and $\mathrm{Np}$ parallel connected PV modules, (4) becomes,

$$
I_{P V}=N_{p}\left\{I p h-I_{0}\left(e^{\frac{q\left(V_{P V}+I_{P V} R_{S}\right)}{\eta k T N_{S}}}-1\right)\right\}
$$

\section{B. PV Characteristics}

The PV model is simulated using Solarex MSX60, 60W PV module. The simulated I-V and P-V characteristics of the Solarex PV module at constant temperature and varying insolation are shown in Fig. 3.2(a) and Fig. 3.2(b) respectively. It can be seen from Fig. 3.2(a) that the decrease in insolation reduces the current largely but voltage fall is small. Fig. 3.2(b) shows that the reduction in insolation reduces the power largely as both voltage and current are decreasing. The effect of temperature on I-V and P-V characteristics of Solarex PV module is shown in Fig. 3.3(a) and Fig. 3.3(b) respectively. It can be seen from Fig. 3.3(a) that the increase in temperature reduces the open circuit voltage largely but rise in current is very small. Fig. 3.3(b) shows that the increase in temperature reduces the $\mathrm{PV}$ output power as the reduction in the voltage is larger than the increase in current due to temperature rise
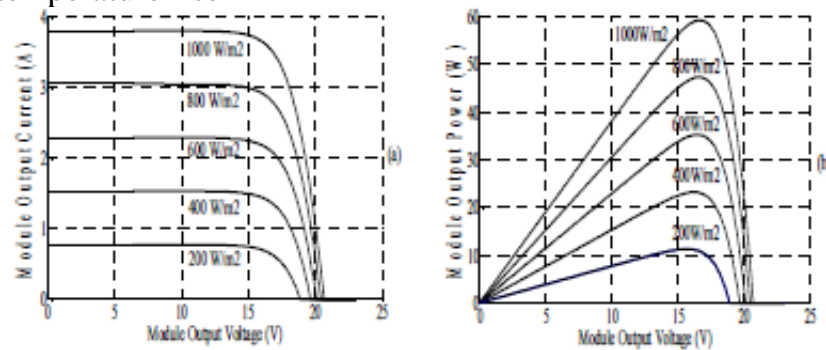

Fig3.1(a) I-V characteristics and (b) P-V characteristics of the Solarex PV module at constant temperature $\mathrm{T}=300 \mathrm{C}$ and varying insolation
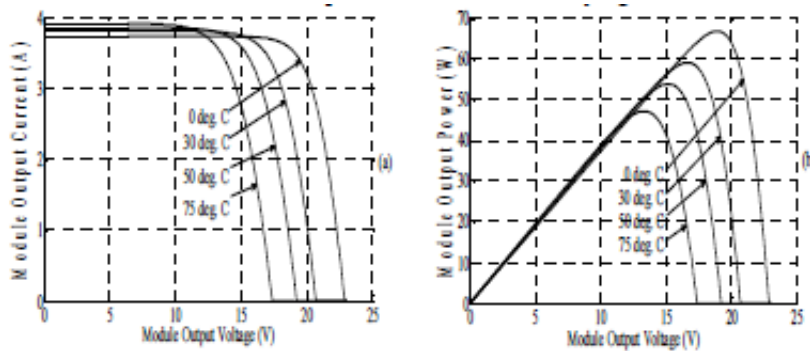

Figure 3.2 (a) I-V characteristics and (b) P-V characteristics of the Solarex PV module at constant insolation $\lambda=1000 \mathrm{~W} / \mathrm{m} 2$ and different temperature. the PV can produce maximum power. The MPP changes with change in insolation and temperature. Therefore, an MPPT controller is required to extract maximum available power from the PV array under varying load and changing environmental conditions. This paper proposes a novel fuzzy logic based MPPT controller.

Fuzzy logic can model or control non-linear systems that are difficult to model mathematically. The fuzzy logic is chosen for MPPT as it gives appropriate performance for varying dynamics, higher convergence speed, robust and simple to design compared to conventional methods. The major objective of the proposed controller is to track and extract maximum power from the PV arrays for a varying solar insolation and cell temperature. The block diagram of the proposed fuzzy logic controller (FLC) is shown in Fig. 3.4. The major functional blocks of the FLC are described as follows:

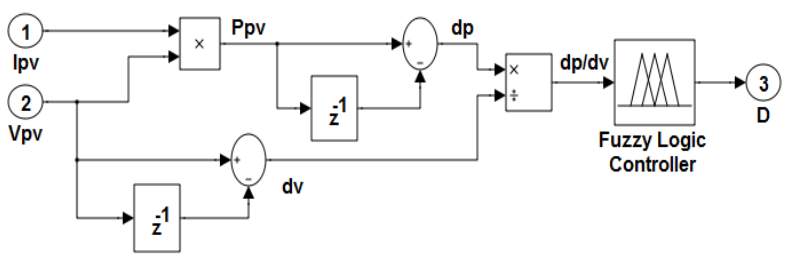

Figure 3.3 Block diagram of proposed fuzzy based MPPT controller

\section{1) Fuzzification}

From the prior knowledge of input and output range, the fuzzification process divides the input and output into linguistic fuzzy sets. The proposed FLC takes single input that is the slope of the P-V curve and gives the duty ratio for switching the boost converter as an output. After sampling the PV array voltage and current, $\Delta \mathrm{P}(\mathrm{k})$ and $\triangle \mathrm{V}(\mathrm{k})$ are determined as follows:

$$
\begin{aligned}
& \Delta P(k)=P(k)-P(k-1) \\
& \Delta V(k)=V(k)-V(k-1)
\end{aligned}
$$

where $\mathrm{P}(\mathrm{k})$ and $\mathrm{V}(\mathrm{k})$ are the power and voltage of $\mathrm{PV}$ array, respectively.

The $\Delta \mathrm{P}(\mathrm{k}) / \Delta \mathrm{V}(\mathrm{k})$ obtained using (3.6) and (3.7) is given as an input to the FLC that generates the duty ratio (D) as an output for providing the switching pulses to the boost converter in order to operate the PV array at MPP.

Depending upon the magnitude of the slope of P-V curve, the proposed FLC divides the input and output into seven linguistic fuzzy sets: negative big (NB), negative medium (NM), negative small (NS), zero (ZO), positive big (PB), positive medium (PM) and positive small (PS). The membership functions of the input and output variables are shown in Fig. 3.5 and Fig. 3.6 respectively. The membership functions for output duty ratio are so chosen that it maintains the de link voltage higher than $650 \mathrm{~V}$ at the same time operate the PV array at MPP. Hence, proposed fuzzy controller eliminates the need for PI controller for dc-link voltage regulation. 


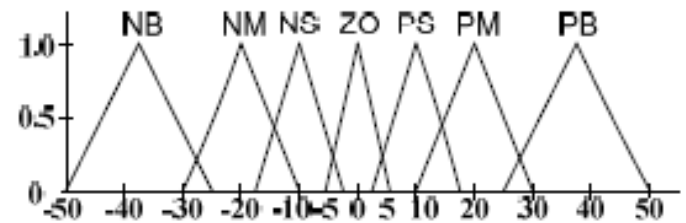

Figure 3.4 Membership function for input variable $(\Delta \mathrm{P} / \Delta \mathrm{V})$

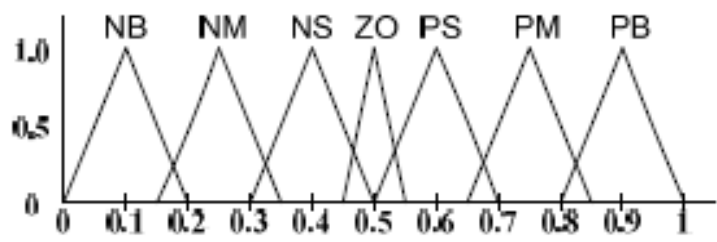

Fig3.5 Membership function for output variable (D)

\section{2) Fuzzy rule base}

The fuzzy rules should be precisely defined based on the knowledge in order to generate an output duty ratio as per the magnitude of the slope of $\mathrm{P}-\mathrm{V}$ curve to operate the PV array at MPP. When the slope of $\mathrm{P}-\mathrm{V}$ curve is positive then to reach towards MPP, the duty ratio of boost converter is decreased in order to increase the PV operating voltage. Similarly, if the slope of P-V curve is negative then to move the operating point at MPP, the duty ratio is increased. The seven rules used for tracking the MPP in the proposed technique are listed in Table II.

Table I FUZZY RULES

\begin{tabular}{|l|l|l|l|l|l|l|l|}
\hline$\triangle P / \triangle V$ & $N B$ & $N M$ & $N S$ & $Z O$ & $P S$ & $P M$ & $P B$ \\
\hline$D$ & $P B$ & $P M$ & $P S$ & $Z O$ & $N S$ & $N M$ & $N B$ \\
\hline
\end{tabular}

\section{3) Defuzzification}

The defuzzification process generates the single crisp value of output duty ratio (D) from the aggregated fuzzy set that includes a range of output values. The widely used centroids (centre of area) method is used to convert the fuzzy subset of duty ratio (D) to real number. It computes the centre of gravity from the final output fuzzy set, and gives a result which is highly related to all of the elements in the same fuzzy set. It is mathematically represented by

$$
z^{*}=\frac{\int \mu(z) \cdot z d z}{\int \mu(z) d z}
$$

where, $\mathrm{Z}^{*}=\mathrm{D}$ which is the output of fuzzy logic controller, $\int$ denotes an algebraic integration and $z$ is the aggregated fuzzy set of output.

The proposed fuzzy logic MPPT controller applies variable steps in duty ratio for controlling the boost converter as per the current operating point and hence, gives faster convergence to MPP compared to conventional algorithms. The proposed algorithm gives robust performance under rapidly changing environmental conditions under which the conventional $\mathrm{P} \& \mathrm{O}$ technique is likely to fail.

\section{CONTROL OF GRID INTERACTIVE PV SYSTEM}

The grid interactive PV system configuration used for simulation study is shown in Fig. 3.7. It consists of two power processing stages: DC-DC boost converter as first stage and three-phase voltage source inverter as second stage. The boost converter stage provides not only the boosting of PV output voltage for grid connectivity but also used as MPP tracker.

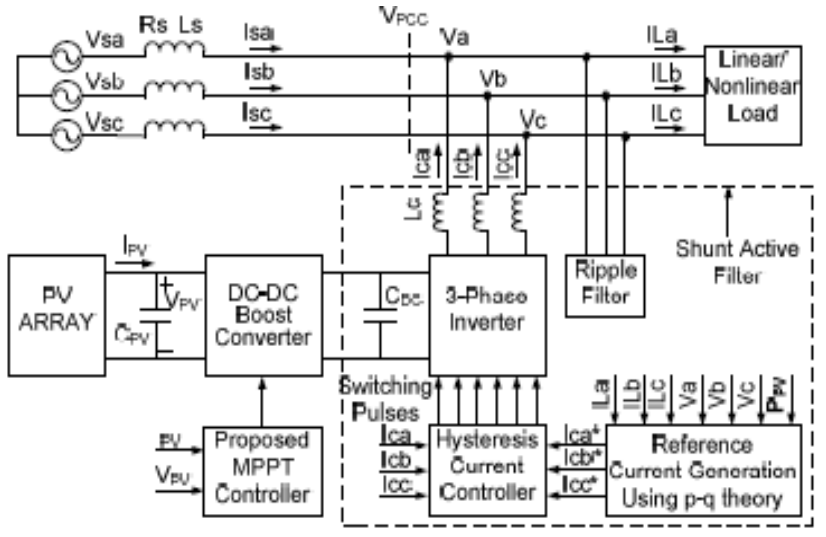

Figure 3.7 Grid connected PV system configuration

By controlling the duty ratio of boost converter using the proposed fuzzy based MPPT controller described in section- III, the current corresponding to maximum power is injected into the grid. The second inverter stage is used for multiple functions: (i) active power injection (ii) harmonic compensation of non linear load connected with the grid and (iii) reactive power compensation of the load. The additional functionality of the PV inverter as a shunt active power filter increases the overall efficiency of the system. The inverter switching signals are generated using the current control technique based on hysteresis current controller.

\section{Reference Current Generation}

The reference current generator block generates the reference current to be injected into the grid upon sensing the voltage at the Point of Common Coupling (VPCC) and load currents using instantaneous active and reactive power $(p-q)$ theory . For the computation of $p$ and $q$, the three phase voltages at the point of common coupling (PCC) and load currents must first be transformed to the stationary two axis $(\alpha-\beta)$ co-ordinates. The instantaneous real and reactive power $p$ and $q$ are determined using equations .

$$
\begin{gathered}
V_{\alpha \beta}=C \times V_{a b c} \\
I_{\alpha \beta}=C \times I_{L a b c} \\
\text { where, } \quad C=\sqrt{\frac{2}{3}}\left[\begin{array}{ccc}
1 & -\frac{1}{2} & -\frac{1}{2} \\
0 & \frac{\sqrt{3}}{2} & -\frac{\sqrt{3}}{2}
\end{array}\right] \\
p=V_{\alpha} \times I_{\alpha}+V_{\beta} \times I_{\beta} \\
q=V_{\alpha} \times I_{\beta}-V_{\beta} \times I_{\alpha}
\end{gathered}
$$

Both instantaneous power quantities $p$ and $q$ consists of dc and ac components. While the dc components $\bar{p}$ and $\bar{q}$, arise due to the fundamental, the ac components $\tilde{p}$ and $\tilde{q}$ 
INTERNATIONAL JOURNAL OFINNOVATIVE RESEARCH IN ELECTRICAL, ELECTRONICS, INSTRUMENTATION AND CONTROL ENGINEERING

are a result of harmonic components. In order to inject active power generated by PV obtained using the proposed MPPT controller and also to provide harmonic as well as reactive power compensation as per the load demand, the reference for active and reactive power are generated according

$$
\begin{gathered}
p^{*}=P_{P V}+\tilde{p} \\
q^{*}=q=\bar{q}+\tilde{q}
\end{gathered}
$$

The ac component $\tilde{p}$ is determined by first extracting $\tilde{p}$, using a very low cut off low pass filter and then subtracting it from $\mathrm{p}$ obtained using (3.12). Finally, the reference currents are generated as per (3.16) and (3.17).

$$
\begin{gathered}
{\left[\begin{array}{l}
i_{\alpha}{ }^{*} \\
i_{\beta}{ }^{*}
\end{array}\right]=\left[\begin{array}{cc}
v_{s \alpha} & v_{s \beta} \\
-v_{s \beta} & v_{s \alpha}
\end{array}\right]^{-1}\left[\begin{array}{l}
p^{*} \\
q^{*}
\end{array}\right]} \\
{\left[\begin{array}{l}
i_{c a}{ }^{*} \\
i_{c b}{ }^{*} \\
i_{c c}{ }^{*}
\end{array}\right]=[C]^{T}\left[\begin{array}{l}
i_{\alpha}{ }^{*} \\
i_{\beta}{ }^{*}
\end{array}\right]}
\end{gathered}
$$

\section{Hysteresis Current Controller}

The hysteresis current controller compares the three phase reference currents $\left(i c a^{*}, i c b^{*}, i c c^{*}\right)$ generated using with the actual inverter currents (ica, icb, icc) and generates the switching pulses as per the logic given below: if ( ica > $\left.i c a^{*}+h b\right)$ leg-a upper switch is OFF and lower switch is $\mathrm{ON}$ if ( $\left.i c a<i c a^{*}-h b\right)$ leg-a upper switch is $\mathrm{ON}$ and lower switch is OFF where, $h b$ is the hysteresis band around the reference current which is usually $5 \%$ of the maximum current to be injected by the inverter. Similarly, control signals for leg-b and leg-c of the inverter switches are generated.

\section{Ripple Filter}

The ripple filter as shown in Fig. 3.7 is used to absorb the switching frequency ripples. The switching ripples are generated due to switching of the inverter using the hysteresis current controller because of practical limitation in minimizing the hysteresis band and also due to switching of the boost converter. The ripple filter is a series $\mathrm{R}-\mathrm{C}$ filter whose component values are so chosen as to absorb the high frequency components in multiple of switching frequency with the constraint that the fundamental current drawn by ripple filter should not exceed $5 \%$ of the maximum load current.

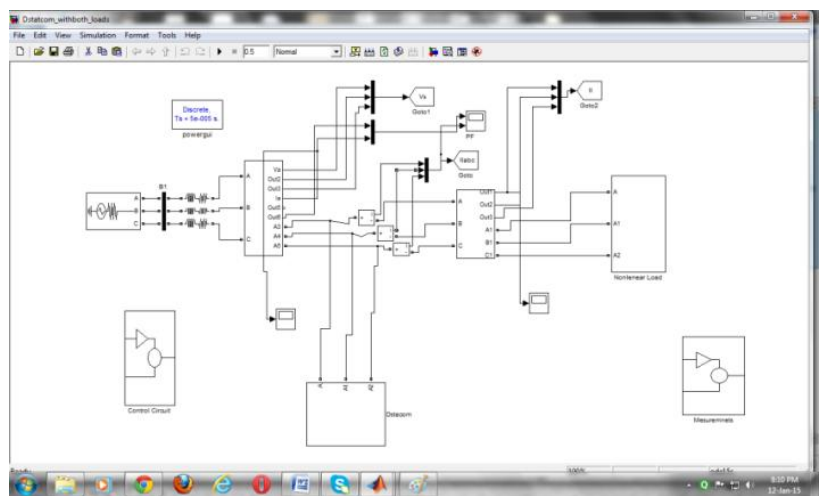

TABLE II PARAMETERS OF PV SYSTEM

\begin{tabular}{|l|l|}
\hline \multicolumn{1}{|c|}{ Parameter } & \multicolumn{1}{|c|}{ Value } \\
\hline $\begin{array}{l}\text { Open circuit voltage (VOC) of a PV } \\
\text { module }\end{array}$ & $21.0 \mathrm{~V}$ \\
\hline $\begin{array}{l}\text { Short circuit current (ISC) of a PV } \\
\text { module }\end{array}$ & $3.74 \mathrm{~A}$ \\
\hline $\begin{array}{l}\text { Module voltage at maximum power } \\
\text { point (Vm) }\end{array}$ & $17.1 \mathrm{~V}$ \\
\hline $\begin{array}{l}\text { Module current at maximum power } \\
\text { point (Im) }\end{array}$ & 3.5 \\
\hline $\begin{array}{l}\text { Maximum Power (Pm) of a PV } \\
\text { module }\end{array}$ & $60 \mathrm{~W}$ \\
\hline Reference temperature & $25^{\circ} \mathrm{C}$ \\
\hline Reference solar radiation (1 sun) & $1000 \mathrm{~W}$ \\
\hline No. of series PV modules in a string & 12 \\
\hline No. of parallel connected PV strings & 10 \\
\hline
\end{tabular}

\section{Output Waveforms:}
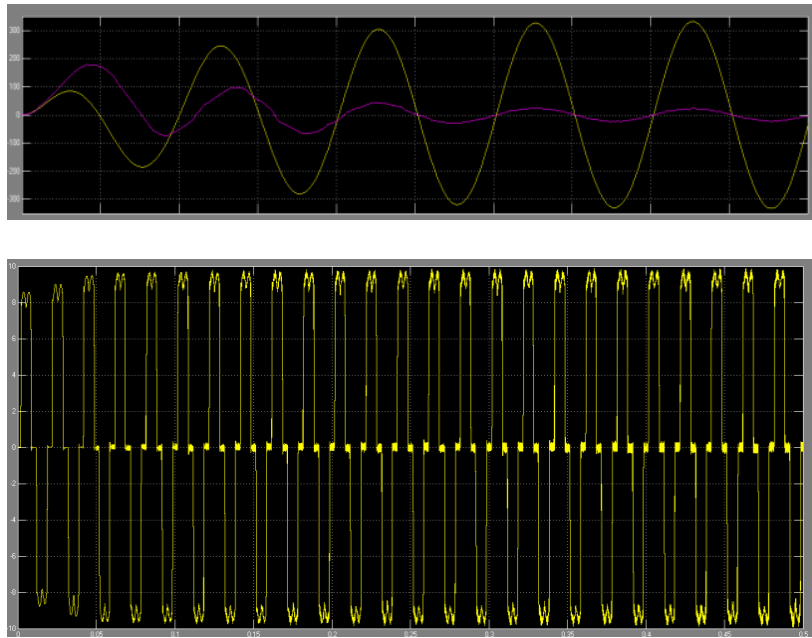

\section{CONCLUSION}

In this paper, multi functional grid interactive PV system is presented using a novel fuzzy logic based MPPT. The proposed MPPT controller is able to track the MPP accurately under uniformly varying as well as rapidly changing insolation and gives faster convergence as a variable step size in duty ratio is applied inherently by the algorithm. The proposed fuzzy controller maintains the dc link voltage within the limit for injecting the power into the grid. Apart from injecting active power during day time, the PV inverter also compensates the harmonics and reactive power during day time as well as at night. The current drawn from the grid is sinusoidal and the total harmonic distortion is well below the specified limit in the IEEE-519 standard. The simulation results validate the performance of grid interactive PV system for both active power injection as well as shunt active power filter functionality to mitigate the power quality issues thus increases the utilization factor of the system. 


\section{REFERENCES}

[1] T. Esram and P. Chapman, "Comparision of photovoltaic array maximum power point tracking techniques", IEEE Trans. on Energy Conversion, vol. 22, No. 2, June 2007.

[2] S. Jain and V. Agarwal , "Comparison of the performance of maximum power point tracking schemes applied to single-stage grid-connected photovoltaic systems", IET Electr. Power Appl., vol. 1, no. 756(5), pp. 753-762, September 2007.

[3] P. Takun, S. Kaitwanidvilai and C. Jettanasen, "Maximum Power Point Tracking using Fuzzy Logic Control for Photovoltaic Systems", International conference of engineers and computer scientists (IMECS), Vol.-II, pp. 986-990, March-2011.

[4] Carlos A. P. Tavares, Karla T. F. Leite, Walter I. Suemitsu, Maria D. Bellar, "Performance Evaluation of Photovoltaic Solar System with Different MPPT Methods", 35th Annual IEEE conference on Industrial Electronics (IECON'09), pp.719-724, 2009.

[5] Subiyanto, Azah Mohamed, and MA Hannan, "Hardware implementation of Fuzzy Logic based Maximum Power Point Tracking Controller for PV Systems", The 4th International Power Engineering and Optimization Conf. (PEOCO2010), pp. 435-439, June 2010.

[6] Md. Asiful Islam, A. B. Talukdar, Nur Mohammad, P K Shadhu Khan, "Maximum Power Point Tracking of photovoltaic Arrays in Matlab Using Fuzzy Logic Controller", Annual IEEE India conference (INDICON), 2010.

[7] B. Alajmi, K. Ahmed, S. Finney, and B. Williams, "Fuzzy Logic Controlled Approach of a Modified Hill Climbing Method for Maximum Power Point in Microgrid Stand-alone Photovoltaic System", IEEE Transactions on Power Electronics", vol. 26, no. 4, pp. 1022-1030, April 2011.

[8] H. Yu, J. Pan and A. Xiang, "A multi-function grid-connected PV system with reactive power compensation for the grid", Solar Energy, 79, pp. 101-106, 2005.

[9] G. Tsengenes and G. Adamidis, "Investigation of the behaviour of a three-phase grid-connected photovoltaic system to control active and reactive power", Journal on Electrical Power Systems Research (Elsevier), 81, 2011, pp. 177-184. 